\title{
LA CREACION DE LOS DIALECTOS GRIEGOS DEL PRIMER MILENIO
}

This article is dedicated to the development of the Greek dialects from the linguistic stage of the second millennium (i. e. from the eastern Greek and the western dialect arrived at Greece in the XIIIth century) about which another article was devoted in Emerita 44, 1976, p. I ss. In the process of creation of the dialects of the first millennium the author states that I) in the XIIIth century eastern and western Greek were closer than afterwards. This is due to the fact that many innovations $(-\tau 1>-\sigma 1$, for instance) were not yet generalized and some doublets like $\alpha \rho / o p$ were still alive. 2) Between the XIIIth and the $X$ th centuries there was a close contact among all the Greek dialects. Some innovations ( $k k^{*} \circ>\pi \circ$, for instance) spread through the whole Greek language. There are also isoglosses which are common to the Ionic-Attic and Dorian, some of which reached the Arcadian-Cyprian and Eolian, or, at least, a part of the latter. 3) From the Xth century on, a clear-cut differentiation of the Ionic-Attic was developped, as well as an interval splitting within the Ionic-Attic, the western Greek and the Aeolian.

\section{GRIEGO ORIENTAL Y GRIEGO OCCIDENTAL,}

\section{r. Los dialectos en el momento de la llegada de los dorios}

Si son ciertas las conclusiones de nuestro anterior artículo, "Micénico, paramicénico y aqueo épico» ${ }^{1}$, los invasores dorios que en el s. XIII a. C. penetraron en Grecia y destruyeron los reinos micénicos, estableciéndose en torno al Peloponeso y en Grecia central, encontraron una serie de dialectos del llamado griego oriental que ni estaban muy distanciados entre sí ni, en realidad, se diferenciaban demasiado del griego occidental de los invasores.

La lista de las principales diferencias entre griego oriental y occidental se encontrará en nuestro artículo mencionado ${ }^{2}$ : se trata fundamentalmente de una serie de innovaciones del griego oriental y, en otros casos,

1 EMIERITA 44, 1976, p. 64 ss.

2 Cf. p. 73 ss. 
de elecciones, a veces en forma diferente según los dialectos. A disminuir la diferencia entre los dos tipos de griego, oriental y occidental, contribuyen los siguientes hechos:

a) Ciertas innovaciones propias del griego oriental no estaban totalmente difundidas, el estadio arcaico continuaba existiendo, al menos en algunas zonas dialectales: $-t i$ junto a $-s i$, $-s s-$ geminada junto a $-s-$, pronombres Tú, toí. Igual en lo relativo a las elecciones: se encontraban ocasionalmente $-\xi-($ y no $-\sigma-)$ en los fut. y aor. de los ver-

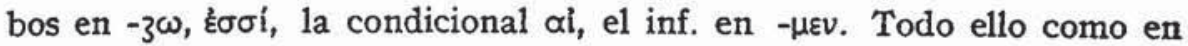
dorio. $\mathrm{Si}$ en griego oriental encontramos hechos como estos ya en aqueo épico ya en tal o cual dialecto paramicénico, hay que tener en cuenta que esta distribución restringida depende de la escasez de nuestros datos: los límites antiguos de las isoglosas eran, sin duda, más amplios.

b) Aunque el griego oriental es fundamentalmente innovador, presenta también en dialectos aislados algunos arcaísmos que es fácil que, en fecha antigua, se conservaran igualmente en tal o cual ámbito dialectal del gr. occidental: así los dat. $\pi$ ó $\lambda \varepsilon t, \pi o ́ \lambda \eta 1$ o la $3 .^{\text {a }} \mathrm{sg}$. en $-t>\varnothing$ en verbos atemáticos o los casos en - $\mathbf{1}$ o en -oío o el dat. sg. en -ol del arc.-chip. o el dat. con દ̌́, ámó de este mismo dialecto. Es imprecisable la fecha en que desaparecieron estos y otros arcaísmos del griego común en cada dialecto; lo más fácil es que en fecha antigua conservaran más difusión de la que conocemos. Baste pensar que una palabra micénica $k o-t o-(i)-n a=\kappa \tau o i ̃ v \alpha$ la reencontramos solamente en rodio y que una palabra también micénica $p i$-je-ra $a_{3}$ corresponde a un $\phi \mathbf{l} \hat{\lambda} \eta$ que hasta el momento era considerado una innovación del gr. helenístico (cf. át. фló $\lambda \eta$, también hay mic. $p i-a_{2}-r a$ ); o pensar en arcaísmos con reparto dialectal "mixto", por ej., -po- secundario en mic., tes., arg., cret. y $\dot{k} v+$ acus. en tes., beoc., arc.-chip. y griego del noroeste.

c) De la misma manera, nada impide que allf donde el griego oriental (o algunos de sus dialectos) presenta un doblete mientras que el occidental sólo muestra una de las dos formas, la que se ha perdido, si realmente remonta al griego común, se haya podido mantener más o menos tiempo en algún dialecto del griego occidental. Esto a veces es demostrable: en cret. hallamos mpotf junto al moti general, en cret. y Tera hallamos $\pi \varepsilon \delta \dot{\alpha}$ en vez de $\mu \varepsilon т \dot{\alpha}$, en diversos lugares hay 0 en vez de $a$ (тóфos, коӨхро́s) ${ }^{1}$. Otras no es demostrable en concreto, pero es

1 Por supuesto, en estos casos y otros se puede hablar también de sustrato aqueo o eolio. Aunque hoy dia, sin negarse completamente la posibilidad, se tiende a reservarla para casos en que fallan otras explicaciones más obvias (arcaismos o formas de dobletes conservadas). Asi procedi ya en La Dialectología... Cf. últimamente, sobre todo el tema, J. L. Garcia Ramón, "El llamado sustrato 
prácticamente una seguridad. Así en el caso de dobletes cuyas dos for-

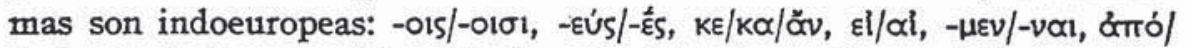

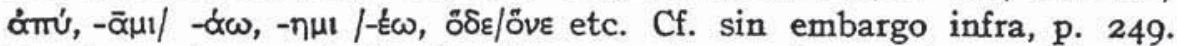
Igual cuando una de las dos formas es innovada: - $\propto \alpha / /$ tol en la des. de $3 .^{2} \mathrm{sg}$. med., quizá las variantes de ípós y las del lesb. y aqueo de que hablamos en "Micénico...», p. Iog. Nótese que si el dor. ha posefdo en algún momento la forma arcaica, pongamos - tol, es el mismo caso cuando el gr. oriental ha conservado parcialmente arcaísmos como-TI, toi. Finalmente, puede darse que las dos formas del doblete sean innovación del griego: éste es el caso de o/a, op/ap y hemos dicho que el desarrollo de las sonanates vocálicas con timbres alternativos remonta al griego común, de modo que nada de extrañar tiene que en griego occidental se haya mantenido algún tiempo.

d) A juzgar por el mic., hay que restituir para el griego oriental la serie labiovelar, conservada en aquel: $k^{\sharp}$, etc. No es dudoso que igualmente se conservaba en occidental y que los tratamientos coincidentes de todos los dialectos en el caso de ciertas posiciones y del gr. oriental $\mathrm{y}$ el dorio ante $e, i$ (por oposición al eolio) remontan a isoglosas recientes: ya lo hemos expuesto al hablar del aqueo épico. Paralelamente, hemos manifestado nuestra opinión de que los grupos de líquida $+s$ o $i$ se hallaban en mic. y en todo el gr. oriental en un estadio del tipo $r h$, $h r$ o en el grupo $a / 0+r / n+i$, en el $-r i \underset{\sim}{i}$ o $i r$. Ese estadio era en realidad griego común $\mathrm{y}$, por tanto, griego occidental: las innovaciones tuvieron lugar en Grecia, mediante isoglosas que rebasaban los límites del griego occidental y el oriental. Cf. p. 249 ss. Por tanto, también en estos puntos el parecido del griego oriental y el occidental en el s. xirr a. C. debía de ser grande, y a juzgar por el mic. habría que añadir otros puntos más, como la conservación de -pm-, -tm- y -ksm-, el dat. $\varepsilon \mu l$ (no éví), la conservación de $\mathrm{F}$ e $i$, etc.

e) Algunos arcaísmos del dor., no testimoniados en gr. oriental, pudieron sobrevivir algún tiempo en tal o cual dialecto: así тદ́тopєs, Evti, fikoti.

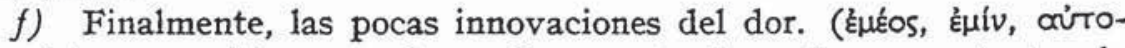
oavróv) son posiblemente desarrollos que tuvieron lugar ya dentro de Grecia. Esta suposición se funda en que los dialectos dorios, en su conjunto, no son innovadores, representan el bloque del griego común no afectado por las innovaciones del griego oriental; $y$ en que, salvo la

eólico: revisión critican, CFC 5, 1973, pp. 233-277, quien reduce el sustrato "é́licos a muy pocos hechos y en una pequeña extensión y aun eso como pura hipótesis; y también Wyatt, art.cit. infra, p. $25 \mathrm{r}$ n. 
últina, estas innovaciones no están en tes. ni beoc. Si esto es asi, tenemos una razón más para afirmar que la proximidad entre griego oriental y occidental, cuando se encontraron en Grecia en el s. xirn, era mayor de lo que podemos pensar a la vista de dialectos que sufrieron luego grandes cambios.

Como podrá observarse, nuestro material para llegar a esta conclusión es desigual: en cierta medida se trata de hechos comprobados, en otra de deducciones, en otra aún de simples posibilidades. E1 resumen, sin embargo, es claro: los dos sectores del griego estaban muy próximos al gr. común; incluso cuando había habido innovación o elección, las formas arcaicas y las no preferidas pudieron continuar vivas en tal o cual ámbito dialectal; y los arcaísmos en general tenían sin duda una difusión hoy imposible de precisar. Pues no hemos de inaginarnos ni el griego común ni el oriental ni el occidental como absolutamente unitarios. Aparte de los dobletes, presentaban sin duda alguna "bolsas" de arcaísmos e innovaciones no completadas: y ello en una distribución imposible de reconstruir a partir de nuestros datos, que suponen un reparto reciente.

\section{Relaciones anteriores y posteriores entre los dos dialectos}

La relación entre los dos griegos en época histórica sólo se comprende si se tiene en cuenta la existencia de varios procesos que se han ido sucediendo y aun a veces han coexistido y que no siempre tienen dirección concordante.

El primer proceso, naturalmente, es el que diferenció ambos dialectos a partir del griego común: es difícil fechar en qué medida transcurrió fuera de Grecia y en qué otra se consolidó dentro de ella. Que hubo esta consolidación es absolutamente seguro: baste pensar que sólo el aqueo conserva arcaísmos "occidentales" del griego oriental que en los demás dialectos fueron eliminados o casi eliminados: тoí,- $\sigma \sigma-1$ $-\sigma-$, etc. $Y$ es lo más probable que algunas innovaciones orientales (o de muchos dialectos orientales) sólo en Grecia se hayan difundido: así oú, forma analógica que presupone una evolución fonética $t u->s-;$ eỉkool, igualmente analógico y presuponiendo fikoti, es decir, $n>a$. Ya hemos dicho, de otra parte, que la eliminación de arcaísmos o soluciones menos favorecidas, que aumentaba la diferencia entre los dos dialectos, sólo gradualmente debió de tener lugar. $\mathrm{Y}$ que las innovaciones del dorio son recientes, nacidas en Grecia. 
Pero nosotros seguimos pensando que el comienzo de la diferenciación de los dos grandes dialectos debió de tener lugar fuera de Grecia. Ello sobre todo porque ciertas elecciones son absolutamente tajantes, dan la impresión de haberse terminado en fecha antigua: - $\mu \varepsilon v /-\mu \in s$ en la r. ${ }^{\text {a }}$ pers. p1., es la más radicalmente lograda. Otras veces donde se da la elección tajante es en dorio: inf. $-\mu \varepsilon v$, condicional $\alpha$, part. $\kappa \propto$. El griego oriental da la impresión de haber emigrado en un estado fluctuante, mientras que el dorio llegó a Grecia, parece, con elecciones bien logradas. Piénsese que se trata de elecciones en sentido que contrasta con casi todo el griego oriental y, desde luego, con el jónico-ático. $\mathrm{Y}$ que, sin embargo, hay huella de confluencia de dialectos más que de oposición cuando los dorios llegan a Grecia.

$\mathrm{Si}$ contemplamos los dialectos dorios, de una parte, y el jónicoático y arcadio-chipriota, de otra, prescindiendo ya de lo que sabemos sobre el griego del segundo milenio, vemos que ciertas diferencias de los dos grupos, oriental y occidental, del griego, se han radicalizado: se han generalizado la asibilación - $t i>-s i$, la simplificación de -ss- procedente de -ss- y -ts-, el art. of, etc.; ciertas coincidencias han quedado reducidas al nivel de arcaísmos aislados en tal o cual dialecto. $\mathrm{Y}$ aumen$\tan$ las diferencias entre el dorio y tal o cual dialecto oriental: caída de la $\mathrm{F}$ y psilosis en jonio, $\bar{\alpha}>\eta$ en el mismo dialecto, etc.

Pero, evidentemente, esto no es todo lo sucedido. Como decimos, han tenido lugar una serie de aproximaciones entre los dialectos griegos, algunas de ellas entre el griego occidental (o el dorio, por lo menos) y sectores muy amplios del oriental o bien todo él. Suelen consistir en innovaciones o elecciones comunes; claro está, cuando sus límites cortan dentro del griego oriental o el occidental, tienden a aislar dialectos dentro de éstos, pero son dialectos que tienen puntos comunes con los de la otra área. A1 mismo tiempo, pero en general con una cronología más baja, se desarrollan las isoglosas propias de cada dialecto en particular, sean innovaciones o elecciones.

El estudio de las isoglosas de fecha griega que rebasan los límites de los dialectos del primer milenio que conocemos tiene trascendencia para la comprensión de la historia de los dialectos griegos en general y de la formación de los dialectos del primer milenio en particular. Piénsese que las diferencias entre los mismos en el segundo milenio, tal como las hemos establecido en el artículo anterior, por lo que respecta al griego oriental, eran mínimas. $\mathrm{Y}$ acabamos de decir que las mismas diferencias entre griego oriental y griego occidental debían de ser muy pequeñas todavía en el s. xirr, ya en Grecia.

Por tanto, no se hace difícil admitir la existencia de esas isoglosas 
que atraviesan las fronteras dialectales. En buena medida puede decirse que esas fronteras apenas eran perceptibles, no tenian la nitidez que tuvieron después, en parte precisamente gracias a estas isoglosas que ahora estudiamos, cuando no invadieron áreas completas. Piénsese de otra parte en la estratificación de poblaciones, tal como tuvo lugar en torno al Peloponeso y en Beocia, Tesalia y Creta, en Asia Menor también: esto facilitaba la evolución en común de los dialectos (sobre Beocia y Tesalia, véase más adelante). Incluso Arcadia y el Atica (con las islas y Jonia), zonas respetadas por los dorios, estuvieron en estrecho contacto con ellos ${ }^{1}$.

En lo que respecta al Atica concretamente hay que decir que no sólo es vecina de un territorio dorio como Mégara, sino que la Arqueología hace ver que a fines del segundo milenio se estableció en su parte occidental una población doria. El mito ático contiene varias referencias a la lucha de los reyes indígenas de Atenas con los beocios.

Podemos distinguir, en términos generales, los siguientes tipos de isoglosas:

a) Isoglosas pangriegas (descartando, por supuesto, los dialectos del segundo milenio). Son las que eliminan con uniformidad ciertos arcaísmos sólo conservados en mic. y aqueo épico. Así, la que elimina las labiovelares labializándolas (ante vocales que no son $e, i$ ), las que eliminan arcaísmos mic. como $-p m-,-t m-, e-m e=\varepsilon \dot{\mu k i}, 1$ la que elige el dat. en $-i$ en vez del en - $e i$ del mic., etc.; las que eliminan arcaísmos

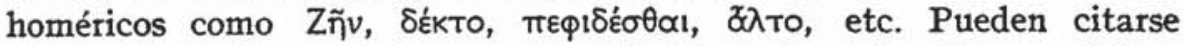
otras que penetraron más o menos profundamente en los diversos dialectos, dejando a veces "bolsas» de arcaísmos: subj. con $-\eta$ en vez de $-\eta$,

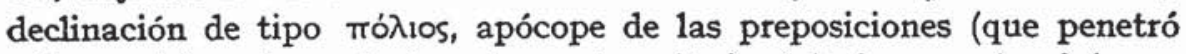
solo parcialmente en jonio y luego fue eliminada), formas de cli z- generalizada, etc. En ocasiones, como queda dicho, quedan arcaís-

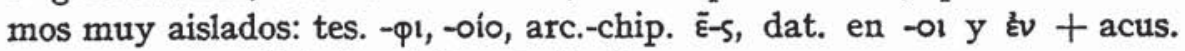
en unos pocos dialectos (cf. supra), etc.

b) Isoglosas del gr. occidental y el grupo del jón.-át. y arc.-chip., es decir, que excluyen el eolio. Aqui hay que incluir, principalmente, la relativa al tratamiento de las labiovelares ante $e$ e $i$, aunque ya sabemos que hay excepciones y problemas: es una solución dental, aunque el arc. presenta huellas de un tratamiento todavía diferente de éste; en los dialectos eolios, en cambio, es, como se sabe, labial. Sin duda, la isoglosa general chocó aquí con otra que la impidió prosperar, al

1 Cf. A. López Eire, "Eñn busca de la situación dialectal del jónico-ático", Simposio de Colonizaciones, Barcelona 1974, p. 247 ss. 
menos en numerosos casos. $\mathrm{Y}$ lo mismo hay que decir de los grupos de líquida $+s$, $i$ : como ya sabemos, el estadio griego común, conservado por el mic., presenta una $h$, salvo, según proponíamos, en $o, a+$ líquida $+i$ (caso en que hay luego una isoglosa pangriega air, oir, del tipo anterior). Pues bien, para estos grupos con $h$ todo el griego admite la solución con alargamiento compensatorio, salvo el tesalio y beocio (y ejemplos en arc.) que llevan sonante geminada (pp, etc.). Son, ya lo hemos dicho, dos soluciones alternativas y hay elecciones independientes. Todavía habría que citar la generalización del gen. sg. -óo y algunas isoglosas más ( $\mu \varepsilon т \alpha \dot{\alpha}$, eliminación del adjetivo patronímico, etc.).

c) Isoglosas del dorio y el jónico-ático. A la luz de todo lo anterior no resultará ya extraño que estos dos grupos dialectales hayan admitido ciertas isoglosas en común: sobre su zona de contacto en Grecia ya hemos dicho algo, aludiendo al influjo dorio en el Atica, y añadiremos más cosas aún. Efectivamente, existen una serie de coincidencias entre los dos dialectos en cuestión, coincidencias que ya mencionó Chadwick ${ }^{1}$. Descartando dos innovaciones que corresponden más bien a nuestro apartado $b$ ), Chadwick señala cinco puntos: los tratamientos

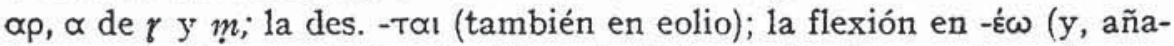
damos, -ów) en vez de la atemática, ámó + gen., ḱvs. Los cuatro primeros representan, después de 10 que hemos visto, hechos de elección dentro de dobletes pangriegos que se han conservado en arc.-chip.; el quinto es igualmente una generalización, la de $-s$ añadida a $\dot{\varepsilon} v$, como se añadía a otros adverbios y preposiciones.

Más, precisamente, diremos que el mic. y arc.-chip. han elegido -Tol frente a - $\tau \alpha$, forma innovada que sustituyó a la primera ya en aqueo épico; que la generalización de - $s$ tras év es igualmente la elección de una innovación; y que el eolio, hemos de verlo, confirma la antigüedad de estadio fluctuante, que en un caso (el de los verbos atemáticos) regulariza en sentido contrario al del jonio-dorio.

A los datos de Chadwick habría que añadir algunas otras isoglosas (algunas, ciertamente, también en eolio): la generalización de las formas

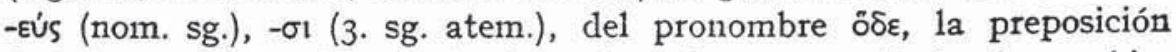

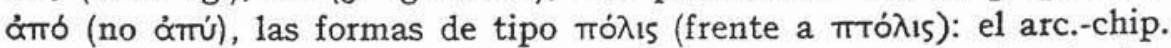
presenta las formas concurrentes, generalmente como segundo término de dobletes. Se trata, una vez más, de elecciones. Un poco diferente es el caso de la evolución de $k i$ y de $t i$ heteromorfémicos: un resultado

1 "The Greek Dialects and Greek Prehistory», Greece and Rome, 3, 1956, p. 43. Cf. también el art. de Wyatt "The Prehistory of the Greek Dialects», TPPhA ror, r970, pp. 557-582, con su concepto del "Mainstream Greekn. 
griego común representable más o menos por $t s$ dio, de un lado, - $\sigma \sigma-$ (en jonio, dorio, tesalio y lesbio); de otro, -тT- (en beoc., cret. y át.); en arc.-chip. quedan huellas de una pronumciación especial. Ha habido, pues, dos innovaciones contrapuestas, cuya difusión no coincide exactamente con los casos anteriores.

Hay que hacer notar que algunas de estas innovaciones no alcanzan a los dialectos del noroeste, más alejados sin duda del punto de contacto con el grizgo oriental: conservan, por ej., ḱv + acus. Estos dialectos, a su vez, desarrollan innovaciones propias, como el dat. pl. atem. en -ols y también otras que penetran en el eolio, así seguramente el dat. pl. en $-\varepsilon \sigma \sigma l^{1}$.

Evidentemente, las coincidencias del dorio y el jónico-ático han dejado aislado al arc.-chip., como dialecto relegado que es. Suponen una zona de contacto que hay que localizar en las fronteras del Atica: aquí ha continuado la evolución en común cuando en el Peloponeso ya no se producía. Pero se nos presenta un problema delicado: el de si no puede imaginarse que algunas al menos de estas elecciones comunes entre formas igualmente arcaicas o entre forma arcaica e innovada o entre innovaciones paralelas no puede haberse dado en fecha muy antigua, antes de penetrar los griegos en Grecia. Es decir: en este caso habría que inaginar la división del griego en oriental y occidental -por lo demás muy incompleta en aquella fecha arcaica - como no produciendo dos bloques claros. Uno de ellos, el occidental y una parte del oriental tendrían un contacto especial, to cual implica un comienzo de diferenciación del jónico-ático desde antiguo.

No es posible decidir tajantemente en esta cuestión, aunque las coincidencias del arc.-chip. no sólo con el mic. y el aqueo épico, sino también, como veremos, con el eolio, más bien hablan en contra de esta hipótesis.

Al acercamiento del dorio a una parte del griego oriental, el posterior jónico-ático, a poco de penetrar en Grecia (y quizá desde antes todavía) siguió evidentemente una época en que el jónico-ático desarrolló sus rasgos independientes, que lo alejaron definitivamente del dorio. Nos ocuparemos de este proceso más adelante. La comunidad de isoglosas jonio-doria es de fecha anterior, cuando aún no se trataba de un dialecto bien dibujado: de los s. XIII y XII a. C., digamos.

d) Otras isoglosas. A título de ejemplo y para que se vea hasta qué punto eran "penetrables» los dialectos griegos independientemente de los límites que acabaron por adquirir, señalemos algunos otros hechos.

1 Cf. Wyatt, "Aeolic substrate in the Peloponneses, $A J P h$ 94, 1973, p. 37 ss. 
Por ejemplo: a veces las isoglosas que unifican a los dialectos del primer milenio hacen alguna excepción dentro de lo que luego será dominio jónico-ático. Se generaliza, por ej., la preposición oúv (dor., eol., arc.-chip., jon.) con la excepción del Atica, que elige la otra forma §ưv: sólo más tarde también aquí triunfa oúv. Inversamente, el dat. pl. en -ors lo hallamos en arc.-chip., dor. y át., mientras que en jon. hay -oırı: son elecciones contrapuestas, si bien en át. -ors sólo muy tarde se afirmó. Otras veces, la discrepancia está dentro del grupo occidental, al tiempo que dentro del oriental: se impone un dat. sg. en - $\omega t$ en dor. y jón.-át., pero en griego del noroeste hay -ot, igual que en arc. (y en beoc. y tes. de la Tesaliótide): pensamos que son dos formas diferenciadas fonéticamente desde el indoeuropeo ${ }^{1}$. Semejante es el caso de la innovación évs arriba aludida: hay $\varepsilon^{2} v$ + acus. en griego del noroeste, además de en arc., tes. y beoc. Hechos como éstos parecen inclinar la balanza en el sentido de que las isoglosas comunes jonio-dorias, que a veces sólo alcanzan a una parte del dominio, se produjeron ya en Grecia.

Por supuesto, otras isoglosas atraviesan las fronteras en formas imprevisibles. Un caso bien conocido es el de las innovaciones que se produjeron allí donde se alteró el grupo -ns- secundario y el -ns final, todavía conservados en mic., tes. y parte del arg. y cret. La discrepancia

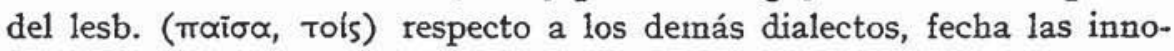
vaciones después de la marcha de los lesbios a Asia desde Tesalia. Pues bien, si es cierto que los demás dialectos coinciden en alargar la vocal, y ello en una fecha reciente en que $\bar{a}$ ya no da $\eta$ en jon.-át., no es menos sabido que en el caso de $e, o$ el alargamiento es ya en el sentido de larga abierta, ya en el de la larga cerrada: este último tipo lo comparten con el jon.-át. una serie de dialectos dorios, la llamada doris mitior, y no sólo para este alargamiento compensatorio, sino también para los de otros tipos. Esste fenómeno de la distinción entre dos tipos de $\bar{e}, \bar{o}$ se da a partir de hacia el año 800 a. C., posiblemente desde Corinto ${ }^{2}$. La evolución lesbia se considera más reciente, de fines del s. vII ${ }^{3}$.

En fin, para no alargarnos en este tema marginal, aludamos a isoglosas interdialectales, como la ya citada $k i \underline{i}, t i \underline{\gamma}>-\tau \tau$ - en vez de $-\sigma \sigma-$ (beoc., cret., át.); $\rho \rho$ de $\rho \sigma$ (en dor., gr. del noroeste, arc. y át.); las del jonio y el lesbio, penetrado por aquél, etc.

1 Cf. Lingïistica Indoeuropea, p. $4^{63}$ ss.

2 Sobre este cambio, cf. Bartoněk, ob. cit., p. 77 ss.

3 Cf. M. S. Ruipérez, "Un fenómeno de palatalización en lesbion, Actas del III Congreso Español de Estudios Clásicos, Maclrid, I968, 3, pp. I93-r99. 
Ast, pues, parece claro que, a la llegada de los dorios, había, con la desaparición de algunos arcaísmos de los dialectos del segundo milenio, una oposición clara de los dos grupos en lo relativo a algunos rasgos. Pero ambos dialectos tendieron a aproximarse mediante ciertas isoglosas comunes de extensión variable. Las más notables son las que fueron comunes al dorio y jónico-ático. También es evidente que la penetración de isoglosas de unos dialectos en otros no cesó nunca. Sólo en fecha reciente se afirmaton en ático, por ej., క̧úv y -ols; y en el s. vi las fronteras del jónico-ático y el dorio eran atravesadas, a veces, por nuevas isoglosas. Pero a partir de un cierto momento se progresó mucho por el camino de una diferenciación de los distintos dialectos. En realidad, cuando el dor. coincidía con el jon-át. pero no con el arc.chip. o el primero con el dor., pero no con el griego del noroeste, y en las demás combinaciones de isoglosas "parciales», todo ello contribuía también a esa fragmentación. Al lado están las innovaciones o elecciones especificas de los dialectos, incluidas las eliminaciones de rasgos arcaicos.

\section{LOS DIALECTOS EOLIOS}

\section{Datos del problema}

Antes de entrar en este nuevo terreno, para acabar de perfilar las líneas generales de lo que pudo ser el desarrollo de los dialectos dentro de Grecia, hemos, sin embargo, de atender a un punto importante que sólo de pasada hemos tocado hasta el momento: el desarrollo de los dialectos eolios. Importante porque no sólo se trata del desarrollo de este grupo y de los dialectos que lo integran, sino porque su estudio es susceptible de confirmar y precisar o, al contrario, poner en duda, todo el esquema sobre el que hemos trabajado hasta ahora. La complejidad del tema nos hacía ver como preferible sentar bases firmes en el resto de los dialectos griegos para penetrar luego en el campo discutido del eolio.

Ya hemos dicho que en tiempos, desconocido el mic. y poco atendido el arc.-chip., el eolio era considerado como la fuente principal del dialecto homérico; según algunos (mediante la teoría del sustrato o variantes de ella, tal la de Porzig), como arranque del arc.-chip. Las coincidencias de mic. y arc.-chip. han arruinado esta teoría. $\mathrm{Y}$, dentro de una tendencia muy generalizada a reducir el papel de los dialectos 
eolios en la historia de los dialectos griegos, hoy en día hay una gran vacilación sobre qué hacer con el eolio.

Los datos principales del problema son que los dialectos eolios del continente (beoc. y tes.) contienen de un lado una serie de isoglosas occidentales, dorias las más, y de otro una segunda serie de isoglosas orientales, principalmente del tipo del mic. y arc.-chip. (y aqueo épico); esto, aparte de algunas peculiaridades propias. Los rasgos de tipo «dorio» y las diferencias con el arc.-chip. llevaron a Risch a separar el eolio del griego oriental; del mismo modo, Chadwick lo interpretó, sin demasiadas precisiones, como una especie de buffer entre los dorios y los micénicos: interpretación no diferente de la mía cuando en La Dialectología..., escrita antes del desciframiento, yo postulaba que el eolio es una zona de transición entre el dorio y el arc.-chip.

Otras veces esa multiplicidad de elementos ha sido interpretada en el sentido de que se trata de un dialecto "mixto", con un superestrato dorio. Esta tesis ha vuelto a ser sostenida últimamente por García Ramón ${ }^{1}$ con la variante de atribuir los elementos dorios a la invasión doria del s. XIII, no a isoglosas posteriores: ello porque los elementos dorios del eolio continental lo abarcan todo él, mientras que los korientales) no.

Esta es una observación justa, pero deja abierto el problema del detalle exacto del proceso y de la relación del pre-eolio con los dialectos paramicénicos. Pues la arqueología y el mito documentan la presencia de los micénicos en todo el territorio posteriormente eolio y, sin embargo, los "micenismos» del eolio aparecen especialmente concentrados en una zona, la Pelasgiótide, la más alejada precisamente del territorio dorio.

En cambio, otra complicación que se presentaba parece estar definitivamente salvada. Se trata de que el lesb. es claro que procede de una migración desde Tesalia, pues comporta elementos comunes con el tes.; pero, al tiempo, se opone a ciertos rasgos del eolio continental, concretamente a los "dorismos». El lesb. tiene kis + acus., psilosis,

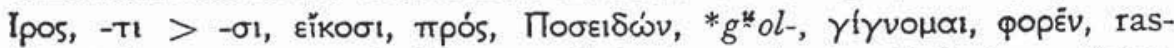
gos todos en que coincide con el jonio contra los dialectos occidentales. Pues bien, a partir del artículo de Porzig es comúnmente aceptado que estas formas, coincidentes con el gr. oriental y concretamente con el jonio, provienen precisamente de isoglosas jónicas, a partir de las vecinas ciudades jónicas de Asia. Con esto se simplifica la cuestión

1 Les origines postmycéniennes du groupe dialectal Éolien, Salamanca, 1975. 
de los orígenes del eolio: los problemas se centran ahora, principalmente, en el continente griego.

Pensamos que los hechos quedan registrados en forma más clara si distinguimos entre rasgos occidentales y rasgos orientales del eolio.

\section{Rasgos occidentales del eolio}

A ciertos efectos, el eolio es un dialecto occidental más, aunque su zona lesbia haya, secundariamente, pasado al dominio oriental. Pero a otros efectos, las isoglosas occidentales sólo afectan a una parte del dominio eolio. Podemos distinguir:

a) Isoglosas occidentales en todo el eolio (prescindiendo de si hay jonismos correspondientes en lesbio). Tenemos arcaísmos como son - $\mathrm{\tau l}$, $-\sigma \sigma-(\mathrm{de}-s s-,-t s-),{ }^{*} g^{*} e l-;$ las elecciones inf. $-\mu \varepsilon v$, condic. $\alpha$; y hay arcaismos en que la coincidencia es con el griego del noroeste, asf $k v+$ acus., los noms. en $-\alpha$ masc. de la primera declinación y los nombres en $-k \lambda e^{\prime} \alpha s$. En algunos casos el arcaísmo afecta también al griego oriental, todo o en parte: espíritu áspero, -ns secundaria, dat. pl. en -o1s, -a1s. En lesbio estos rasgos están ya conservados, ya alterados por influjo jonio;

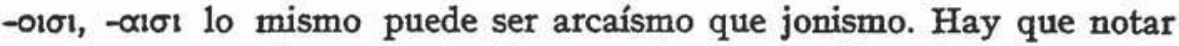
que los rasgos eolios que coinciden con el griego occidental siendo arcaísmos o elecciones, pueden haber pertenecido al substrato pre-griego del segundo milenio, habiendo recibido apoyo, sin embargo, de las isoglosas occidentales.

b) Isoglosas occidentales del beocio y tes. occidental. Hallamos el arcaísmo toí; la elección de los verbos contractos en vez de los ate-

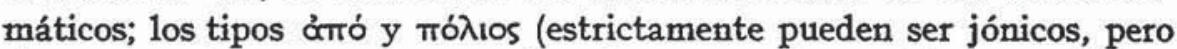
el reparto de rasgos en general sugiere que vienen del dor.); formas de gen. sg. con -óo; además, hay dat. sg. en -ol en beoc., gr. del noroeste y con ciertas dudas en tes. occidental. Algunos de estos rasgos se conservan también en lesbio.

c) Isoglosas occidentales del beocio. Este es el caso de $k \alpha$ frente a $k \varepsilon$ en el resto del eolio; de íapós frente a las otras formas.

d) Isoglosas occidentales del tesalio occidental: $\alpha p$, quizá érel, $\delta \delta \varepsilon$, etc. (v. infra).

La penetración de las isoglosas occidentales en eolio es, pues, variable: ya ocupan todo el dominio, ya las zonas más próximas; y entre ellas hay algunas que dentro del griego occidental sólo afectan al del noroeste. Hay en el territorio eolio una capa de rasgos occidentales que eliminan totalmente a los correspondientes orientales: pero el al- 
cance de su penetración es variable y a veces no hace más que reforzar elementos antiguos del segundo milenio. Está en función, evidentemente, de los rasgos orientales, de que nos ocupamos a continuación.

\section{Rasgos orientales del eolio. Origen del eolio}

Rasgos orientales que afecten a la totalidad del eolio encontramos solamente tres: $\boldsymbol{\gamma}>\circ \rho$, la des. $-\mu \varepsilon \nu$ de $\mathrm{r}^{\mathrm{a}} \mathrm{pl}$. $\mathrm{y}$ el patronímico en -105 . Suponen elecciones dentro de un estadio arcaico. En todos los demás casos los rasgos orientales tienen una extensión más reducida, generalmente están en tes. oriental y, si acaso, en beocio y lesbio. Además, hay que distinguir entre ellos los que son propios de todo el griego oriental y los que aparecen sólo en algunos de estos dialectos. Distinguimos:

a) Rasgos panorientales. Es el caso del art. oi (en tes. y lesb., no en beocio); el de ispós (en beoc. lapós, lesb. Ipos).

b) Rasgos del grupo del arc.-chip., a veces también en mic. o aqueo.

El caso más notable es el del mantenimiento del doblete $\alpha p / o p$, con tendencia a la imposición de la segunda forma; se encuentra en todo el eolio, aunque faltan datos del tes. occidental. Más o menos difusión tienen la yod secundaria ${ }^{1}$ y el paso $\rho t>p \varepsilon$. Lo frecuente es, sin embargo, una limitación de la difusión: los rasgos orientales se encuentran bien en tes. y lesb. ( $\kappa \varepsilon$, verbos atemáticos en vez de contractos) o en

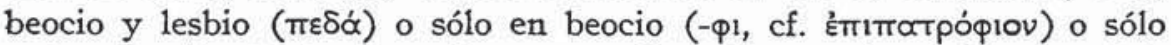

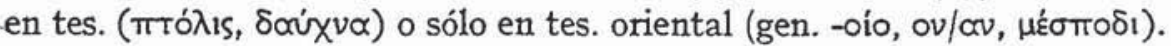
Posiblemente, también son exclusivas del tes. oriental las formas ámú,

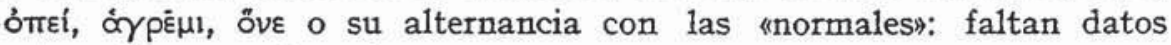
sobre el tes. occidental.

c) Id. del grupo jónico-ático. No los hay fehacientes: el numeral

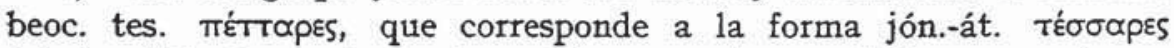

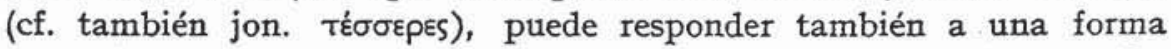
arc.-chip., pues no conocemos el numeral correspondiente de este dialecto. Y la vocalización con $a$ no choca en eolio.

No vamos a repetir los datos sobre la repartición exacta de estos rasgos en micénico y en los dialectos paramicénicos: los dimos ya en nuestro artículo anterior. Salta a la vista que en el dominio eolio se han conservado, aquí o allá, rasgos correspondientes a los de dichos dialectos, a veces mejor que en ellos. $\mathrm{Y}$ que hay algún rasgo micénico que se

\footnotetext{
1 Cf. "Micénico...», p. 95.
} 
encuentra en eolio pero no en los otros dialectos paramicénicos (-olo, $-\phi 1$, adjetivos patronínicos, $\pi \varepsilon \delta \dot{\alpha})$.

Tampoco es dudoso que, en ocasiones, el eolio presenta rasgos pangriegos o dorio-jonios que evidentemente han eliminado el estado más antiguo: no hay huella de -Tol, por ejemplo. Esta eliminación corre a cargo, otras veces, del elemento dorio: hay isoglosas occidentales en todo el eolio, como hay otras que se quedan en las fronteras occidentales del grupo (beocio o tesalio occidental o ambos grupos). Esas isoglosas ntotales" pueden, quizá, explicarse por efecto de una ocupación de un territorio que sabemos por la Arqueología y demás datos que era micénico, por invasores occidentales, dorios. Pero, en último término, esta hipótesis no es necesaria: Dado que existen rasgos pangriegos que unifican al dorio con los otros dialectos y otros que cumplen esa unificación con excepción del arcadio-chipriota (así - $\tau \propto$ ) ), dado además que la mayoría de los "dorismos" del eolio son simplemente arcaísmos, podemos aceptar simplemente la hipótesis de que la llegada de los dorios fue seguida de una difusión de isoglosas en el dominio del eolio, como otras se extendieron, sin duda después, en el del jónico-ático. Esta difusión tuvo lugar antes de que sucedieran en dorio ciertas in-

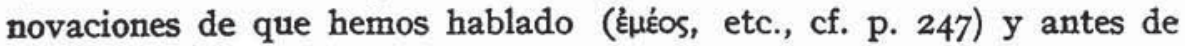
que fueran eliminadas en él cosas que luego se mantuvieron sólo en dialectos del noroeste. Aunque hay que observar que el dat. en -ol (beoc., quizá tes. occidental), por ej., lo mismo puede ser griego oriental (está en arc.) que provenir del griego del noroeste.

Los elementos orientales, en cambio, son sin duda cosa del sustrato micénico o, mejor, paramicénico. Como decíamos, sólo en tres casos ocupan la totalidad del eolio: o $\rho<r$, la I. ${ }^{\mathrm{a}} \mathrm{pl}$. $-\mu \varepsilon v$, patronímicos en -105. En los demás casos están repartidos variadamente, pero es claro que han resistido mejor en las zonas orientales del dialecto.

Así, tenemos en la zona de Beocia y Tesalia huellas de su ocupación por una población micénica: huellas más fuertes en su parte oriental que en la occidental. Donde más vivas han permanecido es en tesalio oriental de la Pelasgiótide y, a veces, en Lesbos. En el oeste es claro que se ejerció un fuerte influjo dorio: pues aqui, aparte de las isoglosas dorias de todo el eolio, entraron otras, con frecuencia comunes con las del jon.-át. Concretamente, casi todas las isoglosas jonio-dorias de que hablamos en p. 25r. Es, muy probablemente, en la zona de contacto del dorio y el griego oriental de Beocia y el Atica donde estas. isoglosas se desarrollaron primero. Pero parece claro, al mismo tiempo, que el griego occidental que influyó sobre el eolio, contribuyendo a crearlo, estaba en una fase más arcaica que el dorio posterior, pues no. 
había aceptado todavía algunas isoglosas dorio-jonias; tenia, además, innovaciones que no penetraron en el dorio, tal el dat. en $-\varepsilon \sigma \sigma \mathrm{l}$, vide infra.

O sea: parece haber habido un primer empuje dorio sobre la posterior zona eolia y luego otro que hizo contacto con el jónico-ático y desarrolló isoglosas nuevas. İl primer empuje debió de ejercerse sobre Tesalia, el segundo a través de Beocia y Mégara: coincide con esta idea el dato de Tucídides I I2 de que los beocios proceden de Tesalia y coincide también con que Tucídides III I02 y Heródoto VII I76 llaman territorio eolio a la zona de Tesprotia y Acarnania y hacen venir de ahí a los pueblos eolios. Como eolios ('abigarrados', 'mezclados') eran considerados los pueblos de dialecto no dorio ni jonio y se veía una clara conexión entre eolio y griego del noroeste. Luego, el desplazamiento del eolio de Tesalia a Beocia rompió la conexión directa del dorio con el jónico-ático, si bien el beocio tuvo un mayor grado de dorización y de pérdida de rasgos paramicénicos de sustrato.

Así pues, si de un lado sabemos que los dorios llegaron como invasores mientras que la población micénica era la originaria; y de otro lado los rasgos occidentales y dorio-jonios del eolio están predominantemente en el Occidente, mientras que los orientales están sobre todo en el Oriente, en un territorio relegado, aislado geográficamente del griego oriental, parece claro que no puede haber otra interpretación de los hechos que la que aquí se propone, precisando tesis anteriores. Una población doria ejerció infujo sobre una paramicénica, pero, con excepción de algunas grandes isoglosas, el territorio oriental se aferró en buena medida al estado de lengua anterior. Y no es precisa la hipótesis de una conquista propiamente dicha.

Este estado de lengua es previo a la escisión de los dialectos orientales ell un grupo jónico-ático y un grupo arcadio-chipriota. Los rasgos orientales del eolio de que hemos hablado eran comunes a los dos grupos en un principio (ov/ $\alpha v, o \rho / \alpha \rho, \mu \varepsilon т \alpha \dot{\alpha} / \pi \varepsilon \delta \dot{\alpha}$, etc.). Claro está, dado que el jónico-ático es el dialecto más innovador dentro del grupo, como veremos, nada de extraño tiene que la impresión general que dejan los dialectos eolios esté más próxima al arc.-chip. Pero insistimos en que no siguen exactamente a esta rama. Se conservan cosas del micénico perdidas en ella, faltan cosas que esta rama desarrolló $(0>v$, salvo en el caso de ártú, que es cosa distinta, cf. "Micénico.," p. 97; el lesb. Ü $\mu \omega$ stc. no es exactamente comparable). Inversamente, hay especialidades del eolio de las que hemos de hablar y que son antiguas.

Dado que algunos de los elementos "orientales" del eolio son simplemente arcaísmos, podría proponerse la idea de que hubieran llegado 
a Beocia y Tesalia con el dorio: por ejemplo, dobletes del tipo ap/op. Ello no es imposible, en algunos casos, pero el reparto geográfico de los rasgos aboga más bien en favor de la otra teoría.

La hipótesis más sugestiva es la de que el dorio que se pone en contacto con los dialectos eolios no ha sufrido sino una serie de modificaciones posteriores. $\mathrm{Ni}$ todas sus isoglosas lograron penetrar en parte del eolio, sobre todo en su zona oriental, que desde pronto tuvo una personalidad lingüística muy acusada y lueggo quedó un tanto aisleda del resto de los dialectos griegos. Este griego occidental transportaba, como decíamos, isoglosas que luego quedaron reducidas al griego del noroeste, siendo eliminadas del dorio o no logrando alcanzarlo; carecía, en cambio, de las isoglosas jonio-dorias, desarrolladas en fecha posterior en las fronteras del Atica. Sólo - $\tau \propto \mathbf{l}$ y - $\varepsilon$ ús son isoglosas joniodorias y, al tiempo, eolias: se impusieron, sin duda, antes.

Cuando posteriormente entraron en Beocia poblaciones procedentes de la síntesis dorio-micénica de Tesalia occidental, el dialecto que llegaba ahora sufrió una dorización especialmente fuerte.

\section{Innovaciones $y$ elecciones propiamente eolias}

Todo esto no es suficiente para plantear una teoría de los origenes del eolio en general y de los dialectos eolios en particular. Hay que hablar de los rasgos propiamente eolios y de su antigüedad, anterior o posterior a la invasión doria. Los rasgos anteriores, si es que existen, tuvieron que condicionar tanto como los micénicos la admisión o rechazo de los rasgos dorios.

E1 problema es que existen una serie de rasgos que son propios de los dialectos eolios o de la mayoría de ellos y que faltan, en cambio, en los demás o, si aparecen, se consideran sustrato eolio o, en Homero, eolismos. E1 problema es el origen y desarrollo de estos rasgos, así como su fecha: ello es decisivo para juzgar el dialecto eolio. Pues son dos posiciones muy diferentes la de, admitido el juego del sustrato oriental y el superestrato occidental en Eolia, postular que en fecha posterior hubo un desarrollo de rasgos propiamente eolios; y la de pensar que el elemento occidental se encontró con un dialecto paramicénico con ciertos rasgos originales y que, tras la difusión más o menos general de rasgos occidentales, comenzó inmediatamente la fragmentación de los dialectos mediante la separación de los beocios hacia el Sur y la migración de los pobladores de Lesbos. 
La primera posición es la de García Ramón en su libro arriba mencionado. Se apoya en dataciones bajas de la vocalización de las sonantes (teoría de Heubeck), de $k^{*} e>\pi \varepsilon$, el dat. en $-\varepsilon \sigma \sigma \mathrm{l}$, $\rho l>\rho \varepsilon$, etc. Una posición diferente sobre la cronología de estos hechos, en parte ya expuesta en nuestro anterior artículo, nos lleva lógicamente a conclusiones también diferentes: que lo que hay de común entre los dialectos eolios proviene ya de la conservación de rasgos paramicénicos antiguos, ya del desarrollo de otros al final de la época micénica, ya de la adopción de rasgos occidentales o noroccidentales.

Ciertamente, algunos rasgos eolios son prácticamente infechables:

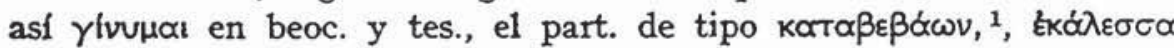
en beoc., lesb. y Hom. (puede ser arcaico o bien lesbismo homérico: en cuyo caso tampoco se fecha la antigüedad). Otros deben ser descartados por referirse en realidad sólo a un dialecto: así los tesalismos - $\tau \theta-$,

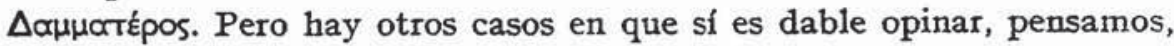
a favor de una fecha pre-doria.

En primer término, cuando lo que han hecho los dialectos eolios es elegir dentro de un doblete del griego oriental o generalizar una evolución ya allí en curso. El eolio, concretamente, ha resuelto a favor

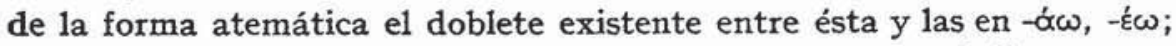
y ha casi generalizado $\alpha \rho$ frente a op. Es sumamente verosímil que estas generalizaciones tuvieran lugar antes de la llegada de los dorios, resistiendo a la solución contraria tanto del dorio como del griego del noroeste. Igualmente, en eolio $\pi \varepsilon \delta \dot{\alpha}$ ha triunfado sobre $\mu \varepsilon т \alpha ́ \alpha$ en beoc. y lesb., lo que se explica mal si esa forma no estuvo también extendida en tes. en un momento dado; por tanto, si en paramicénico formaban doblete y si en dorio ocurre lo mismo pero $\mu \varepsilon т \alpha$ es en general la forma favorecida, parece lógico pensar que la generalización de $\pi \varepsilon \delta \alpha ́$ en eolio sea anterior a la llegada de los dorios: después habría sido más difícil. Finalmente, la evolución $\rho l>\rho \varepsilon$ que encontramos en todo el eolio, pero que responde a una tendencia presente en mic. y aqueo épico ${ }^{2}$, es completamente verosímil que se difundiera antes de que las circunstancias se hicieran adversas con la llegada de los portadores de un dialecto refractario a ella.

Dentro de los hechos de elección el inf. en - $\mu \varepsilon \nu$ nos presenta una situación diferente. Es claro que el eolio continúa una zona del griego oriental que ha elegido $-\mu \varepsilon v$ en vez de $-v a$ en los atemáticos, elección

1 Innovación, por lo demás, no exclusivamente eolia, cf. Garcia Ramón EC 5, 1973, p. 269; arcaica según Wyatt, art. cit., passim; está en Hom.

Cf. «Micértico.... p. 109. 
común al griego occidental: puede haber duda sobre si este contribuyó a imponerla. Pero lo notable es que en beoc., tes. or. y Hom. hay un inf. en - $\mu \varepsilon v$ de verbos temáticos, lo que representa sin duda una innovación frente al resto del griego. Innovación que, por otra parte, halla-

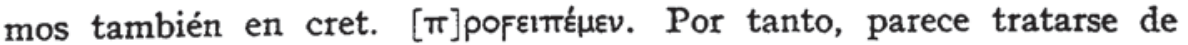
una innovación común al paramicénico de la Grecia central y al aqueo épico, siendo la forma cretense o bien una innovación paralela o un hecho de sustrato de algún dialecto del segundo milenio emparentado con los anteriores. Seria, pues, un rasgo antiguo. $\mathrm{Si}$, al contrario, se trata de un eolismo de la lengua épica, resulta infechable, aunque presupone en todo caso una elección previa de $-\mu \varepsilon v$ en atemáticos. Pero más verosímil es la primera hipótesis, pues el tipo фєрદ́uєv está muy arraigado dentro de las fórmulas épicas, a las que suministra una variante métrica útil, $y$ en cambio no aparece en lesbio, fuente de los eolismos de Homero. Si fue eliminado en lesbio sustituido por $-\eta v$, por influjo jonio, como tambien en tes. occidental, por influjos dorios, parece difficil que haya llegado a Homero a través del lesbio precisamente.

Diferente es la argumentación sobre el carácter antiguo de $k^{*} e>\pi \varepsilon$ y de las líquidas geminadas, que ha sido hecha en nuestro artículo anterior (cf. también supra, p. 247). Si la dentalización de las labiovelares ante vocal palatal no triunfó en eolio en la mayoría de los casos, es porque encontró una competición en la oleada labializadora: luego el fenómeno tiene como terminus ante quem la invasión doria. Igual sucede con la geminación de líquidas en grupos con $s$ e $i$. Ya hemos explicado que esta solución y la del alargamiento compensatorio se contraponen $\mathrm{y}$ los dialectos eligen entre una y otra. En arcadio, laconio y cretense hay huellas de $v v$, etc., aunque se impusiera la otra solución ${ }^{1}$. Pues bien, la generalización de esta solución con geminación en eolio debe haber cerrado el paso, cuando llegaron los dorios, a la aceptación de la solución contraria. Otra vez tenemos el mismo terminus ante quem.

Lo mismo sucede, pensamos, en el caso del dat. pl. en $-\varepsilon \sigma \sigma l$, común a todos los dialectos eolios, al griego del noroeste y a Homero, más apariciones esporádicas. En estas circunstancias, la atribución de las formas del delfio, etc. a un sustrato eolio es más que dudosa ${ }^{2}$. No hay, realmente, argumentos a favor de tal sustrato: hay que pensar o bien que se trata de un rasgo que llega al eolio a partir del griego del noroeste, como otros, pasando a Homero en calidad de eolismo (lesbismo), o bien

1 Cf. Wyatt, $A J P h 94,1973$, p. 44.

2 Cf. Wyatt, art. cit., p. 39 ss. y J. J. Moralejo, Gramática de las inscripciones délficas, Santiago, 1972, p. 146 ss. 
que es una formación antigua, aunque esporádica, de origen analógico, formación que ha llegado independientemente a la lengua épica y al griego del noroeste, de donde al eolio. La primera explicación es, sin duda, la más verosímil; pero aun en el caso de la segunda la conclusión es la misma. Y si se acepta el supuesto sustrato eolio de Fócide, etc., pienso que llegaríamos a igual fecha remota. Supuesto, insisto, sin base ninguna. Lo que dicen los historiadores antiguos sobre el origen de los eolios en el noroeste no tiene otra interpretación que la del origen en el noroeste de ciertos rasgos propios del dorio.

Sin embargo, García Ramón (que en su artículo de $C F A$, I973, p. 260 ss. vacila entre el origen de - $\varepsilon \sigma \sigma \mathrm{l}$ en el griego del noroeste y la teoría del sustrato), en su libro arriba citado sostiene que $-\varepsilon \sigma \sigma l$ es posterior a la invasión doria (igual, como dijimos, que una serie de rasgos eolios) por el hecho de que presupone una evolución $-t s->-s s$ - que es propia del tes. y lesb., pero no del beoc. (que tiene $-t t$-).

Esta teoría me resulta poco convincente. $\mathrm{Y}$ no tanto porque presente un problema para la explicación de formas con - $\varepsilon \sigma \sigma l$ en foc., locr. y otras esporádicas, sino porque la evolución $-t s->-s s$ - es pangriega: coinciden en ella dor., tes., lesb., arc.-chip. y jon.-át., aunque luego el griego oriental simplifique la -ss- (fenómeno seguramente ya iniciado fuera de Grecia). El hecho de que en beoc. y cret. haya -tt- no puede hacernos desligar la evolución del tes. y lesb. de los demás dialectos emparentados y suponer que conservaran -ts-. La isoglosa $-t t$ - es, como hicimos ver en $L a$ Dialectología..., p. 57 , de una difusión más reciente; y concretamente 1a que procede de $-t s$ - tiene menos fuerza expansiva que la que viene de $-t i$ - heteromorfémica, $-k i$ - y $-t u$-, que penetra en ático. Es, posiblemente, una analogía de la misma, pues es lógico que en un momento dado el beocio participara de la isoglosa griega común -ts- > -ss-. O sea, desde mucho antes de la invasión doria existían en todo el griego las condiciones necesarias para que se creara

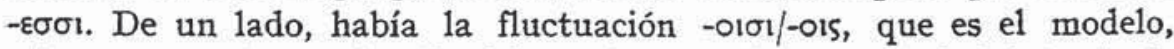
mientras que luego el eolio del continente elige -o15 y la hipótesis de

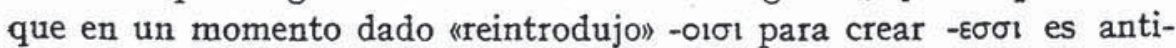
económica e inverosímil. De otro, existía $-\sigma \sigma-$ procedente de $-t s-$ : la hipótesis de que se mantenía -ts- y sólo luego se introdujo - $\sigma \sigma-$ en tes. y leśb., es artificial e increíble. Es imposible comprender los hechos griegos en su conjunto si no se admite que la isoglosa - TT-, sobre todo en el caso de $-t s-y$ de - $t i$ - heteromorfémica, es un derivado de - $-\sigma \sigma-$, no proviene de una forma previa a un doblete $-\sigma \sigma-/-\tau \tau-$ : esto rompería todas las conexiones conocidas de los dialectos.

Inversamente, la difusión en eolio de ciertos arcaísmos dorios que 
en cierta medida se conservaban en micénico (asi $-t i,-s s-$ ), nos lleva a una coincidencia con el dorio, pero no a una fecha posterior a la llegada de este: al menos, para los orígenes del fenómeno.

Así, nosotros al menos, no hallamos caso alguno indudable en que hayamos de atribuir un rasgo paneolio (o que reconstruimos como paneolio) que sea de origen posterior a la invasión doria. Y, en estas circunstancias, rasgos en si dudosos en cuanto a su fecha, que aparecen en los dialectos eolios pero no fuera de ellos, deben, pensamos, atribuirse también al período anterior a la llegada de los dorios. Me refiero

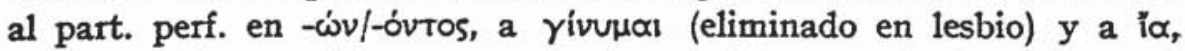
lo mismo si se considera como una innovación a partir de $\mu$ ía, que si se ve en él una forma arcaica, fem. del pronombre $i-1$.

\section{Eolio y dialectos eolios. Eolio, paramicénico y Homero}

Así, no hay huella alguna de una evolución conjunta del eolio en fecha posterior a la llegada de los dorios: si, pese a todo, la ha habido, ha consistido en muy pocos rasgos y de muy poca trascendencia. A partir de ese momento, la evolución del eolio ha consistido en su disgregación mediante dos procesos:

a) El distinto poder de penetración de las isoglosas dorias y occidentales en general, y el distinto poder de resistencia de las isoglosas orientales. De esta manera, quedaron trazadas líneas divisorias dentro del eolio, separando ya el beocio del tesalio, ya el beocio y tesalio occidental del tesalio oriental (con el cual va el lesbio, salvo cuando luego se distanció por efecto de las isoglosas jónicas o por innovaciones).

b) Las nuevas isoglosas intraeolias, elecciones o innovaciones, que también contribuyeron a aislar al beocio del resto de los dialectos eolios y al lesbio del tesalio.

No vamos a entrar aquí con detención en este tema. Pero hay que decir que deben clasificarse en varios tipos, que caracterizan las distintas etapas de la fragmentación dialectal:

a) Un tipo es el que opone el tes. (con inclusión del lesb., aunque aquí puede haber habido innovaciones posteriores) al beocio. Estas innovaciones no son muy frecuentes, si se atribuyen, como hacemos, a fecha anterior -ts- $>-s s-$, el dat. en $-\varepsilon \sigma \sigma 1$, etc.; aun así puede citarse

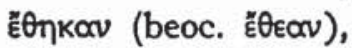

1 Cf. Lingïistica Indoeuropea, p. 821 y Wyatt, lug. cit., p. 40 s. 
b) Contrario a este tipo es el que opone el tes. oriental y lesbio al tes. occidental y beocio: asf en el caso del tratamiento $z$ de $d i, g i$ (frente a $\delta \delta$ ), de la elección dat. en $-\omega 1$ frente a dat. -ol (aunque hay dudas en este punto).

Hay luego los rasgos de los tres dialectos por separado. Son claros los del tes.: elección definitiva de $\mu \varepsilon T \alpha, 3^{\mathrm{a}} \mathrm{pl}$. sec. en $-\varepsilon v, \mu \alpha \dot{\alpha}$, simplifi-

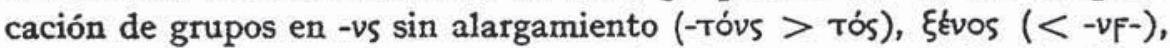
etcétera. También son claros los del lesb., donde, aparte de las isoglosas jónicas, se desarrollaron, sin duda ya en Asia, innovaciones como el inf. en $-\mu \varepsilon^{\prime} \alpha_{1},-1 a$ baritonesis, el tipo $\pi \alpha i \sigma \alpha ;$ también es cierto que el lesb. mantuvo arcaísmos perdidos en el eolio continental pero de los que encontramos ecos en mic. o en otros dialectos no jónicos del griega oriental: $3 .^{\mathrm{a}} \mathrm{sg}$. atem. en ${ }^{*} t$, inf. atem. en $-\varepsilon v(\delta i \delta \omega \nu)$.

En cambio, hasta fecha muy reciente no encontramos prácticamente en beocio una sola innovación que no se realice en común con dialectos occidentales o en forma pandialectal. Es, sencillamente, el beocio el dialecto eolio que más abierto quedó al influjo exterior y ello durante mucho tiempo. E1 centro de la resistencia al influjo occidental estuvo siempre en tes., sobre todo en su zona oriental; y aqui se produjeron también, en un momento dado, algunas reacciones, una nueva afirmación del dialecto local. A su vez, el derivado del tes. en Asia, el lesbio, adquirió en sus nuevas circunstancias de aislamiento respecto al eolio y de contacto con el jonio un aspecto nuevo, mediante el desarrollo de innovaciones, el mantenimiento de arcaismos y, sobre todo, la aceptación de isoglosas jonias.

Volviendo al eolio en su conjunto, que es el tema que aquí más nos interesa, resulta claro que es una parte del dominio del griego oriental del segundo milenio que adquirió, por efecto de la llegada de poblaciones $\mathrm{y}$, sobre todo, de isoglosas pangriegas y occidentales, un nuevo carácter.

El dominio del griego oriental en el cual se implantaron, con mayor o menor éxito, según los casos, esas isoglosas, evidentemente no era idéntico a los que ya conocemos: ni era ello esperable en principio. Hemos visto que conserva huellas de arcaísmos que en otros dialectos paramicénicos no están testimoniados: así -olo, $-\Phi \mathbf{l}$, adj. patronímico; que ha simplificado algunos dobletes (inf. en $-\mu \varepsilon v$, no en $-v \propto$; ; $\kappa \varepsilon$, no ă $v$; $-\tau \alpha$, no - $-\mathrm{l}$ l); que carece de arcaísmos conservados en arc.-chip. y en aqueo, pero tiene con este último dialecto rasgos comunes que faltan en mic. (infs. temáticos en - $\mu \varepsilon v$, aor. ékó $\lambda \varepsilon \sigma \sigma \alpha$ ) y también se da el caso inverso ( $\delta i \delta \omega v$, el mes tesalio $\Delta i \psi$ ios, cf. los $d i$-pi-si-jo de Pilos). A veces las elecciones se realizan en un sentido casi pangriego $(-\tau \propto l)$ pero 
también pueden ser inversas a las habituales (verbos en $-\bar{\alpha} \mu \mathrm{l},-\eta \mu \mathrm{l}$, vocalización preferente de $\boldsymbol{r}$ en $o \rho$ ).

En suma, la semejanza con el arc.-chip. (o el mic.) se funda en la conservación de algún doblete como $\alpha \rho / o \rho, \mu \in \tau \dot{\alpha} / \pi \varepsilon \delta \dot{\alpha}$, aunque hay que advertir que en estos casos se tiende a repartos dialectales (į́pós/i $\alpha$ pós); claro está, a veces no es fácil saber si un determinado rasgo procede de dialectos occidentales o de elección interna. También se funda esa semejanza en la falta de una serie de innovaciones del jonio y del jonio-dorio y a la falta de algunos arcaísmos del jonio o parte de él (dat. p1. en -ā $\sigma$, ६ứv, tóto). Fividentemente, los tres grandes grupos del paramicénico presentaban ya diferencias dialectales y relaciones varias con el micénico y el aqueo épico. Hemos de admitir, pues, la existencia dentro del paramicénico de un protoeolio que, aparte de por arcaísmos y elecciones, se caracterizaba por algunas innovaciones propias, introducidas antes de la llegada de los dorios.

En suma: nos hallamos ante un tercer dialecto paramicénico o un tercer grupo de dialectos paramicénicos, desarrollado en las llanuras de Beocia y Tesalia y conservado pese a isoglosas pangriegas y occidentales $\dot{y}$ a fragmentaciones disgregadoras. Sus rasgos coinciden ya con el mic., ya con el aqueo épico, ya con los de los otros dialectos paramicénicos. Claro está, han llegado a nosotros disminuidos, seleccionados: la medida de coincidencia con el paramicénico del Peloponeso y del Atica no es exactamente determinable.

Lo que es claro es que la coincidencia con el aqueo épico no es estricta: este dialecto, según lo hemos descrito en nuestro artículo anterior, es muy diferente. $\mathrm{Y}$ aquí hemos de añadir algunas cosas a las dichas en el citado artículo sobre el elemento eolio de Homero.

Decíamos allí que el aqueo épico fue interpretado en un momento dado como una mezcla de lesbio y jonio, razón por la cual los aedos que continuaron creando poesía épica en un momento en que el aqueo ya no era lengua viva, añadieron formas efectivamente lesbias (pocas, en realidad) $\mathrm{y}$ formas efectivamente jónicas. $\mathrm{Y}$ añadíamos que esto hace verosímil que todo el proceso hubiera tenido lugar en Asia Menor, donde dichos dialectos convivían y se mezclaban.

Ahora bien, es conocida la existencia de una teoría segín la cual 1a lengua épica tuvo una primera fase tesalia. Dado que hay en Homero

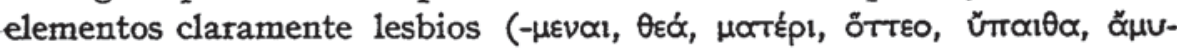
$\delta 15,-\infty \theta \alpha$ en presente), habría en ese caso que admitir la consecución de las tres fases: tesalia, lesbia y jónica, estas dos ya en Asia.

Queremos insistir en que esta teoría no nos parece verosímil. Hay en la lengua épica abundantes elementos arcaicos en modo alguno tes- 
timoniados en eolio del continente; inversamente, falta en ella todo rasgo específico del eolio continental, no lesbio, por ejemplo, -T0-, raíz

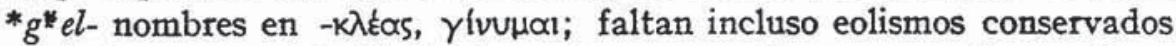
en lesb. como $\pi \varepsilon \delta \dot{\alpha}$. Todo elemento que en Homero pueda reputarse de eolio o es realmente aqueo ( $y$ así ha de juzgarse, hemos dicho, el inf. temático en $-\mu \varepsilon v$ y quizá el tipo ékó $\lambda \varepsilon \sigma \sigma \alpha$, que son las únicas formas sospechosas) o es lesbio (de origen continental como ${ }^{*} k^{*} e>\pi \varepsilon, \sigma v>v v$ 0 innovado).

En realidad, en Tesalia no existieron tras la invasión doria circunstancias objetivas para interpretar la lengua épica como mezcla de jonismos y eolismos. Apenas quedaron alli formas que pudieran entenderse como jónicas. De otra parte, huellas tesalias específicas faltan, como decimos, en la epopeya. Por tanto, la hipótesis de una etapa «tesalia» de la épica no tiene base lingüística alguna: en el fondo no se apoya más que en la localización tesalia de algunos mitos. Pero eso no prueba nada.

La característica de los ciclos épicos consiste, precisamente, en reunir en una empresa común héroes de distintas procedencias, así en la Iliada y la Odisea o en otros ciclos, como el de los Argonautas o la Tebaida. Por otra parte, toda la tradición sitúa en Asia o las islas adyacentes la patria de Homero; y los "viajes" del género épico de Tesalia a Lesbos, de Lesbos a Jonia, carecen de toda documentación y verosimilitud. A esta hipótesis mecánica para explicar la lengua homérica, hemos opuesto la nuestra: interpretación de un dialecto desaparecido a la luz de otros derivados en definitiva de uno próximo a él y con inserción de formas de estos nuevos dialectos. Todo ello en una misma área geográfica, Asia.

Homero, precisamente, fecha el desarrollo de los dialectos lesbio y jonio, señala incluso el estado de su evolución en el s. virr. La mayor parte de las innovaciones de ambos dialectos estaban ya cumplidas.

Limitándonos ahora al lesbio, que es el que nos ocupa en este momento, hemos de recordar en primer término que la mayoria de los supuestos lesbismos de Homero son simplemente aqueísmos, según hemos expuesto ${ }^{1}$. Incluso cosas que están sólo en Hom. y lesb. son aqueísmos (cf. "Micénico...", p. I09). En cuanto a los lesbismos propiamente dichos, están bien en las "interpretaciones» de fonemas o grupos de fonemas desaparecidos del lesbio y jonio, bien en adiciones posteriores según el modelo de la mezcla de formas jonias y lesbias que se creían ver en el aqueo o se introducían en las (interpretaciones». Entraron ya en la

1 Cf. «Micénico...», p. 108 ss. 
lengua épica en su última fase, en los $\mathrm{s}$. del $\mathrm{x}$ al virr. Pues bien, respecto a los lesbismos hay que notar:

a) Recogen un estadio del lesbio en que todavía se conservaban el inf. en $-\mu \varepsilon v$ temático y el nom. sg. asigmático de la primera declinación masc. (testimoniado en beoc., tes., en lesb. sólo por los gramáticos).

b) Ciertos lesbismos o eolismos en general no útiles métricamente

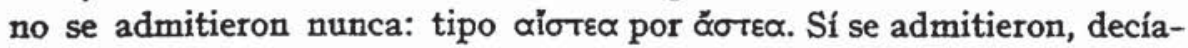
mos, cuando sustituían a formas ya desaparecidas (labiovelares, $-s r-$, etc.).

c) Entraton innovaciones lesbias como el inf. en - $\mu \in v \alpha_{1}$ (posiblemente un cruce de $-\mu \in v$ y el $-\nu \propto$ jónico), $\mu \propto x t \hat{k}$ ı (si no es innovación más extendida, cf. "Micénico...», p. Iog), ötrєo (generalizado descle ótri).

d) En cambio, no entraron en la lengua épica una serie de eolismos (lesbismos) que, sin duda, no se habian desarrollado todavia en

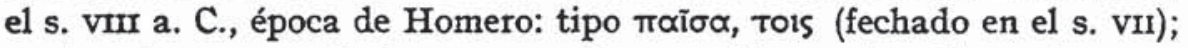

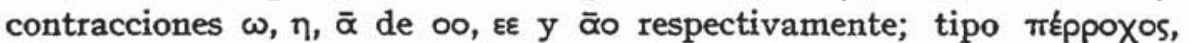
Пе́ppouos. Muy raras y dudosas son las huellas de otros fenómenos.

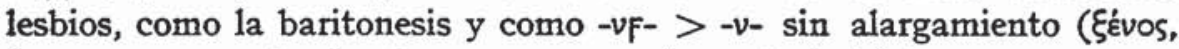
forma que por lo demás no es necesariamente lesbia).

Para comprender bien nuestra argumentación hay que tener en cuenta que las formas que se aceptaron para sustituir a las aqueas anteriores (-ns- secundaria y -ns final, $-n u-$, vocales en hiato) fueron precisamente las formas jónicas. Si formas $-n s-,-n s$, que se mantenían en tes., fueron eliminadas del texto homérico, esto quiere decir que se había producido una relajación de la $n$, pero que no se había llegado en lesb. a la solución posterior con $i$ : por eso se aceptó la solución jónica $\pi \widetilde{\sigma} \sigma \alpha$, por lo demás ya en el s. virr, puesto que la $\bar{\alpha}$ no se altera. En cuanto a la elección de ov, $\varepsilon$ (no $\omega, \eta$ ), en las contracciones, lo más verosímil es que las evoluciones del jónico sean más antiguas que las del lesbio; o, en todo caso, que sean más o menos contemporáneas y los aedos hayan elegido las jónicas, como es lo más frecuente, allí donde hay la doble posibilidad. Pero la diferencia de comportamiento respecto

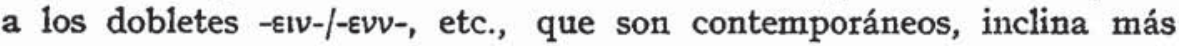
a pensar lo primero.

En cambio en el caso de - $n$ u- hay que decir que la solución jónica

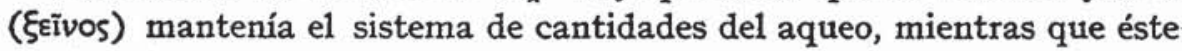
se alteraba en lesbio; de alí el casi absoluto predominio de las formas jónicas. Volviendo a -ns piénsese, en cambio, que la razón de la falta de $i$ no puede ser de este orden: tos ante consonante, tois y tous eran métricamente equivalentes, pero sólo hay toùs. No podemos sino pen- 
sar en, primero, la alteración del grupo en Asia; y, segundo, la rápida imposición del alargamiento en jónico, mientras que tois, aún no fijado o en trance de fijarse, en modo alguno podía tomarse por un elemento antiguo, digno de entrar en la lengua de la epopeya, ni siquiera en el s. vir.

\section{LOS DIALECTOS PARAMICÉNICOS Y SU EVOLUCIÓN}

\section{La creación del dialecto jónico}

Prescindiendo alora de los rasgos diferenciales del ático, que nunca parecen remontar a una fecha muy antigua, llamamos dialecto jónico a la fase antigua de lo que más precisamente se denomina otras veces jónico-ático. Vamos a repasar los datos dentro de los dialectos paramicénicos, tratando de sacar conclusiones sobre la evolución de los mismos y, concretamente, sobre la creación del jonio.

Hemos visto en páginas anteriores que los dialectos paramicénicos del Sur, aquellos que dieron origen al arc.-chip. y al jon., diferian en algunas pequeñas cosas de los de la Grecia central, de donde surgió el eolio. Bien es verdad que el eolio no acabó de cobrar sus rasgos propios hasta que absorbió, con mayor o menor extensión, ciertas isoglosas occidentales muy características. Pero comparándolo, de una parte, con los dialectos paramicénicos del Sur y, de otra, con el mic. y el aqueo épico, hemos concluido que conservaba arcaísmos como -oío, $-\phi 1$, los adjetivos patronímicos; que, todo o parte de él, había hecho elecciones como la de los verbos atemáticos en vez de los contractos; y que también presentaba algunas innovaciones propias, como el tratamiento de las labiovelares ante $-e,-i$, la geminación de las líquidas; y había generalizado tratamientos como $\mathrm{pl}>\rho \varepsilon$. Es ciertamente imposible fechar la antigüedad de estas y otras elecciones e innovaciones dentro del paramicénico de la Grecia central y también es imposible dictaminar cuándo desaparecieron en el paramicénico del Sur arcaísmos aquí conservados en mayor o menor extensión. Aun así, parece claro que el dialecto eolio estaba en trance de formarse mediante la consolidación de una serie de isoglosas, algunas a todas luces más recientes que el mic. de las tablillas.

Algunos de los rasgos de este paramicénico de Grecia central o protoeolio - como se le quiere llamar--- evidentemente faltaban en el paramicénico del Sur. Pero otros rasgos del proto-eolio los encontramos en el dominio paramicénico, y concretamente en arc.-chip. (cf. supra. 
p. 266). No que todos los arcaísmos del arc.-chip. estén en proto-eolioni al revés; pero no existen en proto-eolio arcaísmos comunes con el jonio y opuestos al arc.-chip. Es que dentro del grupo del Sur, el jonio. es un dialecto innovador; raras veces en cambio podemos descubrir una innovación del arc.-chip. que sea reciente, un fenómeno aislado. en el mundo de los dialectos griegos: - tu por -тo, por ej. Se trata de un grupo dialectal relegado, fosilizado, sin influjo, por ello, ni en los dialectos hablados ni en los literarios, como hemos dicho ya. Una prueba más de ello es que, aunque penetrado por algunas isoglosas pangriegas, hay otras muchas que sólo afectaron al dorio y jonio; no al arc.-chip. $y$, a veces, tampoco al eolio, otra zona fundamentalmente relegada, sobre todo en Tesalia. Lesbos es cosa diferente.

De todas maneras, sigue siendo evidente que el jonio es originariamente una parte del paramicénico del Sur. Realiza una serie de elecciones entre rasgos que tenemos manera de comprobar que estaban presentes en ese paramicénico, mientras que a veces no hallamos huella de ellos en el proto-eolio o paramicénico de la Grecia central.

Muy concretamente, en jon. encontramos la condicional $\varepsilon l$, elección

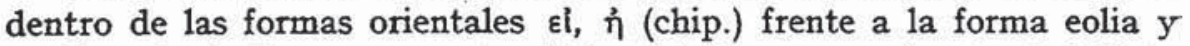
occidental $\alpha$. Encontramos también el inf. en $-v \alpha$, frente al doblete $-\nu \propto 1 /-\mu \varepsilon v$ del paramicénico (arc.-chip. - $v \propto ı$, eol. $-\mu \varepsilon v$ ); ỡ $v$, de que hay huellas en arc. ${ }^{1 ;}$ mpós (no hay huella en arc.-chip., pero sí en Hom.; hay, sin embargo, mic. pa-ro que es una variante fonética); formas con $-\sigma \omega,-\sigma \alpha$ de verbos en $-\zeta \omega$, mientras que el arc.-chip. vacila, a veces

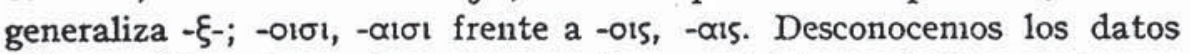
del arc.-chip., de modo que no podemos establecer si éste es el caso

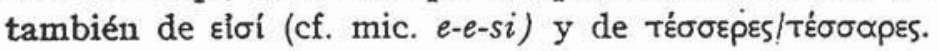

Todas estas diferencias del jon. respecto al arc.-chip. son, como bien puede comprenderse, infechables. Son elecciones que pueden haber sucedido en cualquier momento: elecciones de no demasiada trascendencia para el panorama general de los dialectos. Lo más probable es, desde luego, que desde antes de la llegada de los dorios comenzara una cierta diferenciación, caracterizada por estos rasgos, entre el paramicénico del Peloponeso y el del Atica, de la misma manera que uno y otro difieren en cierta medida del mic. y el aqueo épico. Es, insistimos, la del jonio la zona innovadora, porque frente a ella suelen estar unidos el paramicénico del Peloponeso y el de la Grecia central (proto-eolio).

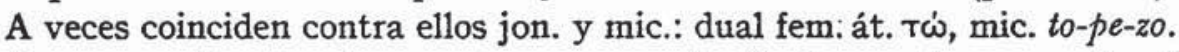
Aunque, naturalmente, no siempre es así. Puede suceder que sólo el

1 Cf. Micénico...n, p. 76. 
proto-eolio haya conservado un arcaísmo: así los adjetivos patronímicos. $\mathrm{O}$, inversamente, que el arcalsmo esté sólo en jonio o una parte de él:

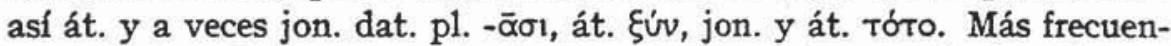
tes son, de todas maneras, las innovaciones propiamente jonias, de que hablaremos a continuación, y cuya antigüedad es, con frecuencia, difícil de fijar, pero que en algunos casos pueden llegar al paramicénico. Así, seguramente, el $-\sigma \alpha v$ de la $3 .^{a} \mathrm{pl}$. de pretérito, que se encuentra en aqueo épico y que rehace una antigua forma en $-\alpha v$ mantenida en arc.-chip. y eolio.

Así podemos fijar algunas diferencias y algunos puntos comunes entre los dialectos paramicénicos, como podemos señalar también sus semejanzas y diferencias con el micénico y el aqueo épico. Pero no podemos, ciertamente, pasar de una aproximación de unos pocos datos en realidad.

Ahora bien, los rasgos que más separan al jon. del arc.-chip. son aquellos en que coincide con los dialectos occidentales $o$, al menos, con el dorio; rasgos que también se extienden a veces al eolio o a parte del eolio. Evidentemente, un dialecto paramicénico muy poco diferenciado quedó mucho más aislado del paramicénico del Peloponeso o protoarcadio-chipriota en el momento en que desarrolló una serie de isoglosas comunes con los dialectos de tipo dorio, en la zona de contacto del Atica con Mégara y Beocia. La mejor prueba de que esto es así es el hecho de las coincidencias entre arc. y chip.: puesto que este dialecto había emigrado del Peloponeso antes de la llegada de los dorios y el arc. coincide sustancialmente con él, ello es una prueba más de la falta de contagio de todo el grupo frente a las isoglosas dorias.

Las isoglosas a que nos estamos refiriendo han sido ya estudiadas por nosotros. Nos referimos principalmente a las preposiciones ámó,

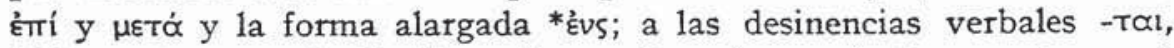

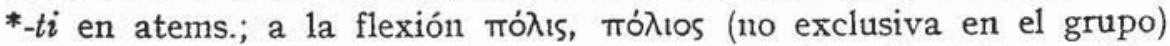

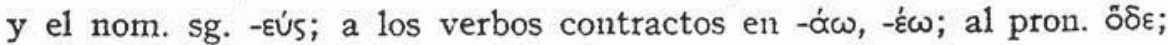
a la elección definitiva de $\gamma>\alpha p$ como resultado de las sonantes vocálicas.

No es imposible, ciertamente, que algunas de estas elecciones hubieran comenzado a imponerse antes de la llegada de las isoglosas dorias: de la misma manera que a una fecha anterior hay que atribuir, evidentemente, la imposición de - 15 y en ella ha podido comenzar la difusión de $\mu \varepsilon т \alpha \dot{\alpha}$ (en dor. hay a veces $\pi \varepsilon \delta \dot{\alpha}$ ). En definitiva: si es cierto que debemos admitir un comienzo de diferenciación del paramicénico del Atica antes de la llegada de los dorios, es claro que cuando llegaron se desarrolló con ellos, durante un tiempo, una especie de Sprachbund 
que acabó de aislar a esta zona del paramicénico del Peloponeso, relegado a Arcadia y aislado allí; y también, del de la Grecia central. Claro está, el influjo dorio no fue suficiente para borrar los rasgos de unión con los demás dialectos paramicénicos, los que habían quedado en zonas relegadas. En algún caso incluso se mantuvieron arcaísmos ya eliminados en éstas: asi, el doblete §úv/ớv (luego distribuido entre

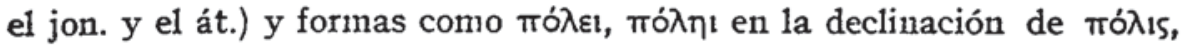
el dat. pl. en -̄̄ot, tóto.

Lo que es claro es que todos estos rasgos del jónico estaban ya logrados en la fecha de redacción definitiva de los poemas homéricos y aun antes, cuando acabó de constituirse la lengua épica: pongamos en el s. Ix a. C. Y no sólo estos, sino una serie de innovaciones que caracterizan la lengua jónica y que aparecen casi siempre en dicha lengua épica, en general como alternativa a formas más arcaicas que integran con ellas dobletes de utilización métrica. $\mathrm{Y}$ alguna elección exclusiva.

Nos referimos sobre todo a los hechos siguientes:

a) $\bar{\alpha}>\eta$, innovación cuyo comienzo se coloca hacia el año Iooo; su fase $\vec{a}>a$ estaría concluida hacia el 800 , mientras que en Naxos $\mathrm{y}$ otras islas no se llegó a $\bar{e}$ hasta el s. $\mathrm{v}^{1}$.

b) $\bar{\alpha} \varepsilon>\bar{\alpha}, \bar{\alpha} \circ, \bar{\alpha} \omega>\omega$.

c) Metátesis de cantidad $\eta \circ>\varepsilon \omega, \eta \alpha>\varepsilon \tilde{\alpha}$, sólo culminada en ático y generalmente con $F$ intermedia, pero testimoniada ya en Hom.

d) Diferencia de abertura en las vocales $\bar{e}, \bar{o}(\eta / \varepsilon, \omega / o v)$, siendo cerradas en caso de contracción o alargamiento compensatorio. Innovación realizada con el corintio y otros dialectos (doris mitior) y fechada hacia el s. $x$.

e) $v>\ddot{v}$ (comenzado hacia el 700 , terminado en muy varias fechas $y$ no realizado en Eubea) ${ }^{2}$.

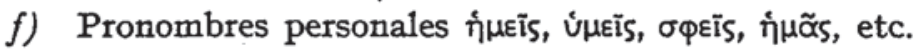

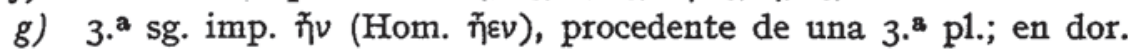
y arc.-chip. hay ĩs.

h) $3 .^{\text {a }}$ pl. en $-\sigma \propto \alpha v$ (cf. supra, p. 27r).

i) $-v$ efelcística en $3 \cdot^{a} \mathrm{pl}$. (esporádica en otros dialectos).

j) Falta de apócope en las preposiciones (sin duda, nivelación de un estadio fluctuante que los demás dialectos tendieron a llevar a la apócope).

k) $\mathrm{kl}$, no ai (en Hom. hay ambos).

l) हีтвроS por व̊̃tepos.

1 Cf. Bartoněk, ob. cit., p. 99 ss.

- Cf. Bartoněk, ob. cit., p. I Io ss. 
Los hechos métricos excluyen que la mayor parte de estas formas hayan sido introducidas en el texto homérico a posteriori. Parece, pues, que ya se daban en el s. Ix: la excepción es ü.

Así, a la luz de las vacilaciones y dobletes homéricos y aun extra-

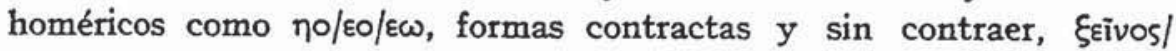
乌́vvos etc., parece que en el s. virI a. C. el jonio había desarrollado prácticamente todos sus rasgos característicos, pero algunos estaban en pleno período de difusión. Es sabido, por ejemplo, cómo en el s. v a. C. continuaba distinguiéndose en las islas jónicas del Egeo entre la $\bar{e}$ procedente de $\bar{a}$ y la procedente de $\bar{e}_{j}$ cómo sólo en ático culmina la metátesis de cantidad, etc.

En suma: suponemos tres fases en la creación del dialecto jónico:

a) Una leve diferenciación debida casi siempre a elecciones del paramicénico del Atica, que, por otra parte, presentaba ya, como los demás dialectos paramicénicos, algunas diferencias respecto al micénico y el aqueo épico. La diferenciación fue gradual: en una cierta medida fue aumentada por las innovaciones de otros dialectos (recuérdese lo que hemos dicho sobre los pocos arcaísmos jonios) o por las del propio jonio. Pues entre las que hemos mencionado hay algunas que pueden remontar a la última fase del paramicénico: concretamente, algunas de las morfológicas y lexicales a partir de $f$ ), aunque no podamos demostrarlo estrictamente.

b) La llegada de los invasores dorios creó una serie de isoglosas dorio-jonias que tendieron a aislar al jonio del arc.-chip. (si bien este aceptó algunas isoglosas pangriegas) y aproximarlo en cierta medida al dorio.

c) Posteriormente, entre el s. xir y el Ix a. C., tiene lugar la creación definitiva del jonio, mediante una diferenciación creciente respecto al dorio: diferenciación basada en innovaciones fonéticas y morfológicas, sobre todo.

\section{Historia posterior de los dialectos griegos}

Ahora bien, el jonio continuó diferenciándose cada vez más entre los s. Ix y $\mathrm{v}$ a. C.: en parte, por la difusión de las isoglosas surgidas antes; en parte, por la creación de otras nuevas (contracción $\varepsilon \circ>\varepsilon u$ etcétera).

Simultánea a esa diferenciación fue la escisión del dialecto entre el jonio propiamente dicho y el ático: escisión paralela a la de los dialectos eolios y a la de los dialectos dorios, que son contemporáneas. 
Hay que notar que en el jonio propiamente dicho conocemos muy pocas diferencias dialectales, pese a la afirmación de Heródoto (I I42) de que las habia. Fundamentalmente es un dialecto unificado: si en su formación intervinieron los dialectos paramicénicos del Peloponeso, cono se desprende de varias leyendas sobre la fundación de las ciudades jónicas de Asia, evidentemente se fundieron con la aportación procedente del Atica. Pues las diferencias entre jónico y ático son recientes, derivación de una fase común.

Ciertamente, en ático puede haberse conservado un arcaísmo desapa-

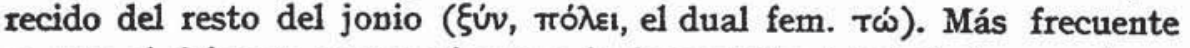
es que el ático se caracterice por la imposición total de innovaciones como la metátesis de cantidad, por la elección entre fluctuaciones del

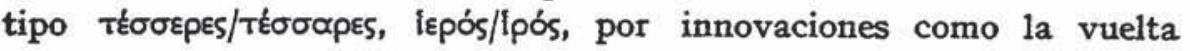
de $\eta$ a $\bar{\alpha}$ tras $\rho, 1, \varepsilon \circ$ el gen. $v \in a v i o v$, por isoglosas compartidas con otros dialectos como $\pi$ y $p p$. También en lo relativo al vocabulario presenta el ático una diferenciación gradual, según hemos establecido en otro lugar ${ }^{1}$.

De todas maneras, no puede esquematizarse la historia de los dialectos griegos a partir del s. IX a. C., que habría que escribir alguna vez, en el sentido de que consiste sólo en una serie de escisiones dentro de los tres grupos del jonio, dorio y eolio. Por lo menos en los dos primeros continúa la difusión de rasgos comunes: acabamos de decirlo para el jonio, lo hemos dicho también para el dorio ${ }^{2}$. Hay luego, evidentemente, la diferenciación de los dialectos de cada rama. Pero existen también influjos entre dialectos de ramas diferentes, tales el del jonio en el

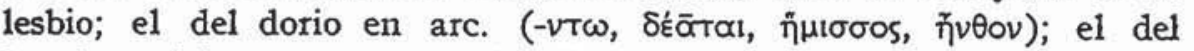
beocio en ático; otros en que los dialectos se entrecruzan, en lo relativo a la abertura de las vocales y en otros puntos, en forma que nada tiene que ver con las clasificaciones habituales de los mismos. Piénsese en la fuerza de las isoglosas externas en casos como la imposición tardía en ático de oúv o de los dativos pl. -ols, -als.

\section{CONCLuSIÓN}

Con esto damos por terminada nuestra revisión de la historia de los dialectos griegos en este artículo y el anterior. Historia parcial, puesto

1 Cf. "Orígenes del vocabulario áticon, EMERITA 21, 1953, pp. 123-624; 22, 1954, pp. 258-270.

Cf. supra, p. 250. 
que apenas si dejamos esbozado el proceso de fragmentación dialecta 1 a partir del s. IX, ni entramos en el de la nueva unificación a partir del Iv, ni tocamos más que en un solo punto - el del dialecto homéricoel problema de los dialectos literarios.

El griego del segundo milenio, en parte establecido fuera de Grecia (dialectos occidentales), en parte en ésta, se nos presenta dividido en los dos grupos occidental y oriental que sabemos, cuya diferenciación no era muy grande. Quedaban en cada uno de ellos zonas que conservaban arcaísmos o formas dobles preservadas en el otro grupo. Por otra parte, el griego oriental, pese a la enorme extensión que ocupaba, desde Tesalia a Creta, desde Mesenia a Asia, conservaba una notable unidad.

Sin embargo, en vísperas de la llegada de los dorios el griego oriental habia producido dialectos levemente diferenciados. De un lado dos lenguas literarias, el micénico y el aqueo épico: el primero derivado de la lengua de Creta, el segundo de la de algún otro lugar. De otro tres dialectos "paramicénicos", con base en el Peloponeso, Atica y Grecia central, respectivamente, y cuyas diferencias eran sin duda muy pequeñas. Sin embargo, estos comienzos de fragmentación al final de la época micénica hay que considerarlos dentro de un cuadro más amplio: desde el momento en que el griego oriental, separado del griego comín, se había establecido en Grecia, las diferencias respecto al que llamamos griego occidental habian ido aumentando. Imaginamos que habían comenzado fuera de Grecia; pero ell ésta la difusión de las isoglosas orientales se había hecho más completa y varia, sin cluda habían surgido incluso ahora.

La llegada de los dorios en el s. xirl trastornó todo este panorama. Desaparecidas las lenguas literarias micénica y aquea (mejor dicho, desaparecidos los dialectos en que se basaban), el griego oriental en general quedó más separado del occidental que, además, desarrolló algunas innovaciones propias.

Pero la comunidad de los griegos no quedó rota: la difusión de ciertas isoglosas pangriegas, como la evolución de las labiovelares lo prueba. En realidad, la nueva comunidad de los griegos se centró fundamentalmente en los dialectos dorios. De un lado, implantaron algunas de sus características más destacadas en el paramicénico de la Grecia central. De otro, desarrollaron en comunidad con el jonio una serie de rasgos que diferenciaban a ambos dialectos del arcadio-chipriota y de las zonas del eolio que habian resultado menos accesibles. Efectivamente, los dialectos paramicénicos del Peloponeso y de Tesalia 
resultaron los menos permeables, en buena medida permanecieron en estado estacionario, arcaizante.

En realidad, todo esto viene a coincidir con el nuevo cuadro que los arqueólogos e historiadores tienden a darnos respecto al fin del mundo micénico. A la antigua idea de una invasión doria repentina, una inundación que anega los reinos micénicos, sustituye hoy la de un hundimiento de los reinos micénicos que posiblemente no se debe a los dorios, sino a los "pueblos del man" o a luchas internas, seguido de un largo período de unos 150 años, el submicénico, en el que convivirían poblaciones dorias y micénicas ${ }^{1}$. Es notable que, en este período, en ocasiones hay continuidad en el poblamiento de las ciudades, mientras que, en otros casos, pasa un largo tiempo de abandono: no parece tratarse del asentamiento de un pueblo conquistador. Por otro lado, en ninguna parte hay una clara ruptura cultural: todos los nuevos desarrollos encuentran precedentes en la edad anterior. Es durante este largo período, sin duda, antes de consolidarse los estados dorios de un lado y los no dorios del otro, cuando tuvo lugar el fenómeno de aproximación de los dialectos.

Esta fase de tendencias unificadoras, con las excepciones mencionadas, fue seguida luego, quizá desde el s. $x$, por otra en que se tiende a una mayor diferenciación. Es sobre todo el jonio el que se separa de los demás dialectos, adquiriendo rasgos propios y escindiéndose luego en jonio y ático; pero también se escinden los dialectos eolios (el lesbio bajo el influjo del jonio, aparte de sus innovaciones propias); y dentro del propio territorio dorio se crearon diferentes dialectos. Este proceso debió de culminar en el s. Ix.

Todavía después se difundieron isoglosas que tendían puentes entre dialectos vecinos, aunque no estuvieran emparentados, en puntos concretos. Pero podemos decir que en el s. vI a. C. los dialectos están perfectamente fijados en lo esencial. Es a partir del s. v y, sobre todo, del IV, cuando cobra fuerza la nueva corriente unificadora en torno al ático, la que crea la koiné.

Al mismo tiempo, hacia el s. Ix había quedado constituida la lengua épica, a base de einterpretaciones" y añadidos lesbios y jónicos al aqueo épico que continuaban cultivando los aedos. Esta lengua ejerció luego un influjo decisivo en la creación de las otras lenguas literarias: sobre

1 Cf. J. Chadwick, The Mycenaean World, Cambridge, 1976, p. 188 ss.; B. C. Dietrich, The Origins of Greek Religion, Berlin, 1974, p. 200 ss., con bibliografía. 
todo en el jonio epizante de la elegía y el dorio más o menos homerizado de la lírica coral. Son lenguas internacionales, propagadas por poetas viajeros que son verdaderos continuadores de los aedos épicos. Pero también ejerció influencia en las lenguas epicóricas convertidas en literarias por obra de los creadores de la monodia: los líricos lesbios, Arquíloco, etc. Y, luego, en la prosa jónica.

Del segundo milenio a la koiné, de Homero a las demás lenguas literarias, no hay una evolución en línea recta ni un árbol de los dialectos griegos. Las tendencias diferenciadoras $y$ las unificadoras alternan y se combinan. Pensamos que las leves diferenciaciones de los reinos micénicos, los fenómenos de integración y desintegración al tiempo promovidos por la invasión doria, la progresiva diferenciación y escisión, a partir de entonces, de los dialectos, y, luego, la nueva convergencia en torno al ático, son los momentos decisivos.

Así, una representación en árbol de los dialectos griegos sólo presentaría una parte de los hechos. Esta representación seria como sigue:

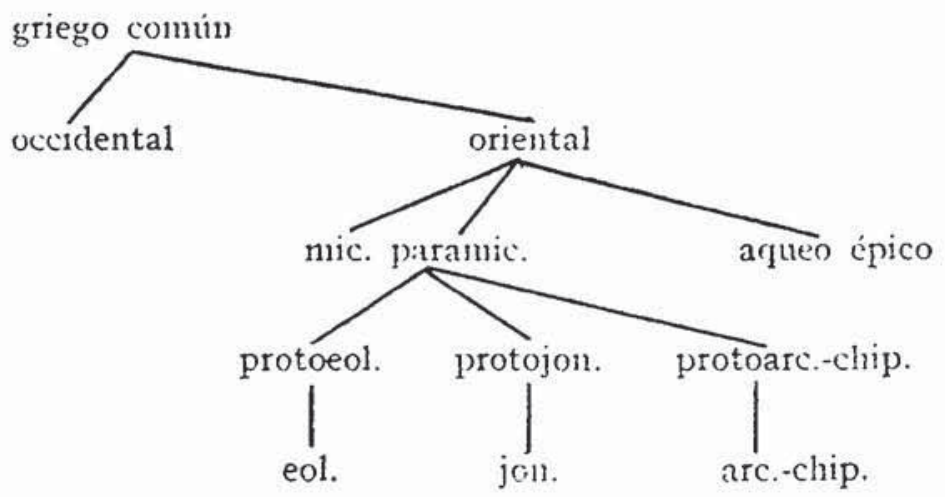

Pero el cuadro debe ser completado con las conexiones de tipo horizontal: las de tipo pangriego, las que introducen isoglosas dorias en el eolio o en partes de él, las que llevan a una confluencia de dorio y jonio, las que introducen jonismos en el lesbio, otras posteriores más limitadas; $y$, en el plano literario, las que crean el dialecto homérico tal como lo conocemos y las que crean las lenguas literarias posteriores.

A manera de ejemplificación señalemos algunos de los desarrollos horizontales que en la fase más antigua, hasta el año 900 digamos, tuvieron lugar entre los dialectos "naturales": 


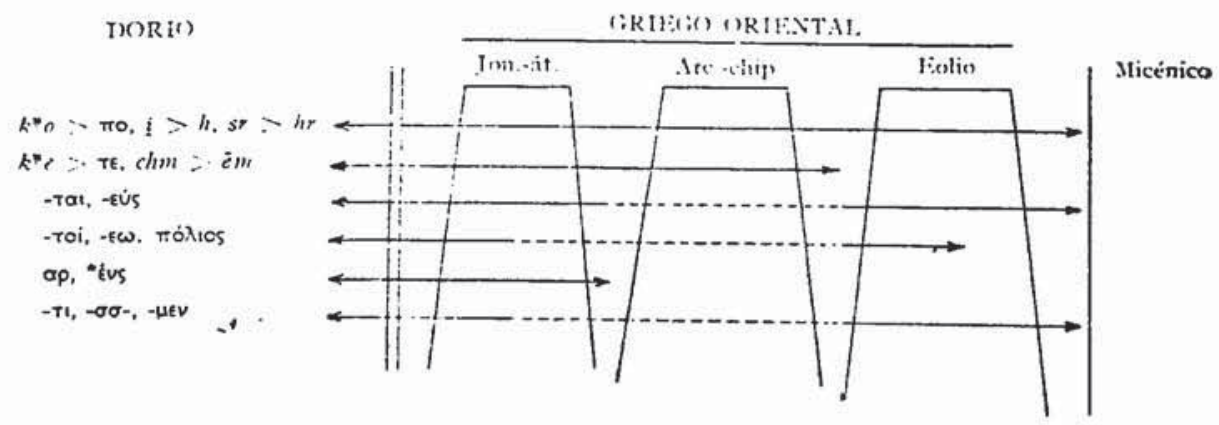

Aunque, en términos generales, los períodos de desarrollo vertical y horizontal se alternan. Fue la llegada de los dorios la que puso de nuevo en contacto a los dialectos griegos que estaban en trance de diferenciación; pero este mismo hecho, así como innovaciones posteriores, fueron el punto de partida para nuevas diferenciaciones. El proceso, sin embargo, comenzó a invertirse desde fines del $\mathrm{s}$. $\mathrm{v}$ mediante el nuevo proceso unificatorio representado por la creación de la koiné.

Francisco R. Adrados 